\title{
Determinants of Health Information-Seeking Behavior: Implications for Post-Treatment Cancer Patients
}

\author{
Minsoo Jung
}

\begin{abstract}
Health information-seeking behavior (HISB) is active need-fulfillment behavior whereby health information is obtained from diverse sources, such as the media, and has emerged as an important issue within the transforming medical environment and the rise of medical consumers. However, little is known about the factors that affect HISB and its associations, and the health outcome of HISB. The aim of this study was to examine individual and social contextual factors associated with HISB and to systematically review their effects on health status among posttreatment cancer patients. Individual determinants of HISB included demographic factors, psychosocial factors, perceived efficacy and norms, and health beliefs. Contextual determinants of HISB encompassed community characteristics, neighborhood social capital, and media advocacy. Improving through factors on these two levels, HISB raised individuals' self-care management skills and medical treatment compliance, and enhanced shared decision-making and medical treatment satisfaction. Moreover, because HISB can differ according to individuals' social contextual conditions, it can give rise to communication inequalities. Because these can ultimately lead to health disparities between groups, social interest in HISB and balanced HISB promotion strategies are necessary.
\end{abstract}

Keywords: Health information-seeking health communication - mass media - cancer patients

Asian Pac J Cancer Prev, 15 (16), 6499-6504

\section{Introduction}

Health knowledge is necessary for personal healthcare management. The public obtains such health knowledge not only from healthcare providers, but also through daily media exposure. Health information became highly universalized amid a wave of health news, pharmaceutical advertisements, and health websites coupled with the recent emergence of user-generated Internet content (i.e. blogs) based on diverse information and communication platforms. Despite the abundance of health information, however, huge disparities exist between individuals in their levels of health knowledge, their interest in health information, and their health information-seeking behaviors (Viswanath, 2005). Therefore, numerous advanced countries spotlight health informationseeking behaviors (HISBs) as a key element of health communication.

Free access, active search, and accurate understanding and use of health information heavily influence a healthy lifestyle, early diagnosis of disease, disease control, participation in medical decision-making, understanding of therapeutic processes, and the treatment of ultimately terminal patients or post-treatment cancer patients (Van der Molem, 1999; Viswanath et al., 2012). Formerly, doctors acted as the sole providers of health information, but technological advances in communication and information dissemination created an environment that offers diverse sources of information related to health management (Fallowfield et al., 1995). In response, citizens began to actively utilize such media to satisfy their growing health information needs. Accordingly, it is necessary to have a precise understanding of cancer patients' and individuals' HISBs and to examine multidimensional factors associated therewith, thereby making them available for use in health promotion campaigns. This paper examines individual and contextual factors affecting those HISBs in order to comprehend their impact on a population's health status, thereby exploring which mechanisms of the social structure set those HISBs into motion.

\section{Definition and Characteristics of HISB}

CHISB is the intended behavior of an individual to satisfy perceived needs for health information (Johnson, 1997). Therefore, passive searching for health information, such as accidental exposure of media or scanning, is not regarded as HISB (Shim et al., 2006). HISB is connected with various individual and contextual elements and influences population health status in a mutually interdependent manner. Various information channels, mostly classified as people (e.g., healthcare provider, family, and friends) or media (television, radio, newspaper, book, and magazine), are included in the process of HISBs. Often, plural channels are employed to verify the adequacy of the information collected (Muha, 1998). Meanwhile, the use of the Internet has rapidly increased due to the easy access to a vast information pool it provides (Viswanath et al., 2007). In fact, two thirds of adults in the U.S. use the Internet as the main source of 
health and medical information (Maguire et al., 1996; Fox and Jones, 2009), though the proportion varies depending on social class (Viswanath et al., 2006; Viswanath and Kreuter, 2007).

Healthcare providers are the most favored sources of health information, as they are considered to be the most reliable (Serin et al., 2004; Johnson and Meischke, 1991; Hesse et al., 2005). Nonetheless, proxy information agents (PIAs), such as family members and friends, help patients and cancer survivors find useful information (Echlin and Rees, 2002; Jung et al., 2013; Eng et al., 2012). PIAs function as health information sources and information channels promoting patients' HISB and enhancing the quality of health information (Jung et al., 2013). Health information collected by HISB is widely used in the selection of medical treatment methods, symptom management, prognosis, preventive behavior, survivorship, coping ability, doctor-and-patient communication, end-of-life care, and informed decisionmaking (Lewis et al., 2009; Borgers et al., 1993; Butow et al., 1997).

Previous studies have analyzed types of health information, information sources, frequency, strength, and trends over time, but could not provide a consistent operational definition of HISB. Other studies attempted to standardize HISB (Miller, 1987), but this concept was not widely used. Consequently, it is necessary to look into the mechanism of HISB and clarify the influential factors of HISB.

\section{Individual Determinants of HISB}

\section{Demographic factors}

The correlation between socio-demographic characteristics and HISB has been studied relatively frequently, and the general conclusion is that women, non-Hispanic whites, young and highly educated people, and high-income earners are very likely to practice HISB (Duggan and Bates, 2008; Eakin and Strycker, 2001; Mayer et al., 2007; Rutten et al., 2006). First, women search for health information more actively than do men, and the reason may lie in gender differences in the sociocultural context (Rutten et al., 2006). Second, non-Hispanic whites participate more actively in HISB than do other races (Nguyen and Bellamy, 2006). In fact, minority groups such as African-Americans and Hispanics are relatively more passive regarding HISB and more dependent on medical providers (Maliski et al., 2006; Levinson et al., 2005; Vanderpool et al., 2009). While the reasons for this are uncertain, it seems to be an effect of the combination of language barriers and disproportionately low educational levels. Third, as age increases, HISB generally decreases (Duggan and Bates, 2008; Rutten et al., 2006; Lambert and Loiselle, 2007). The reason for this is that senior citizens experience impediments in using telecommunication devices such as the Internet (Cotton and Gupta, 2004). Fourth, as the educational level and health literacy increase, so does HISB (Arora et al., 2008; Kelly et al., 2009; Sullivan et al., 2009; Galarce et al., 2010). As is well known, educational levels and health literacy have a high correlation, and the higher they are, the more active HISB is (Institute of Medicine, 2004; Shieh et al., 2009). Finally, the higher the income, the greater the possibility of accessing quality health information (Ramanadhan, Viswanath, 2006; Mayer et al., 2007). In particular, in the case of media whose scope of use broadens according to a payment plan, such a correlation becomes even clearer. For example, it is not easy for low-income groups to freely acquire health information through smartphones (Viswanath, 2005). Moreover, these groups lack the time and motivation to participate in HISB.

\section{Psychosocial factors}

An individual's need for health information and appropriate HISBs are generated from changes in his or her health conditions, disease type, and psychological processes (Johnson, 1997; Pinquart and Duberstein, 2004). For example, HISB is touched off by special triggers, influential incidents, and external stimuli (Lenz, 1984). In fact, tendencies to monitor or avoid information stem from the psychosocial situation that causes an individual stress. Consequently, the amount of health information that a cancer patient actively seeks can differ considerably depending on whether he or she seeks that health information routinely or seeks/avoids particular and specific health information (Case et al., 2005; Feltwell and Rees, 2004; McCloud et al., 2013; Echlin and Rees, 2002; Jung, 2014). Moreover, HISBs can be promoted or discontinued depending on how attractive the benefit reaped from the search is vis-à-vis the seeking cost (Lenz, 1984).

In the end, whether an individual's health information needs will promote HISB is tied to his or her psychosocial characteristics (Kahlor, 2010). For example, existing studies have reported that the greater an individual's information search skills (i.e., self-efficacy), the more likely he or she is to search for the necessary information (Bass et al., 2006). As a result, an individual's psychosocial factors directly affect HISBs. In the case of critical diseases such as cancer, the response of avoiding health information generally occurs when the patient experiences negative feelings, including terror, fear, and enervation (Irving and Lloyd-Williams, 2010; Whetten et al., 2008). When the perceived threat is great, the possibility of information avoidance increases (Radecki and Jaccard, 1995). Consequently, it is necessary to fully take into consideration the role of psychosocial factors in the chain process of HISBs (Czaja et al., 2003; Borgers et al., 1993; Jung, 2014).

\section{Perceived efficacy and perceived norms}

Self-efficacy, also known as information efficacy, is a core concept in health behavior models such as social cognitive theory for it increases the likelihood of HISB (Arora et al., 2008; Bass et al., 2006; Bandura and Cervone, 1983). The level of self-efficacy depends on the individual, but it is generally recognized that HISB is more prominent in individuals with a high level of selfefficacy (Bass et al., 2006; Bandura and Cervone, 1983). This bilateral relationship between HISB and self-efficacy is also shown in the fact that the latter increases when an individual finds useful health information through 
HISB. Of course, HISB works differently under different circumstances. If the cost-effectiveness is disappointing, then information seeking might not be successful even when the self-efficacy is high (Fishbein et al., 2002). Similarly, the perceived norm that HISB participation benefits an individual also affects HISB (Ajzen, 1991). If family members and friends consider exchanging health information as a valuable activity and often engage in such activities with an individual, then HISB can be further enhanced. In contrast, in an environment where health is overlooked, the HISB decreases due to lowered perceived value and norm (Brashers et al., 2002; Loiselle et al., 2006).

\section{Health belief}

People are often afraid of negative health information and tend to avoid it. Information, such as the fact that a disease leads to death when it further develops or is left unnoticed, causes negative emotions, such as helplessness (McCloud et al., 2013). Therefore, HISB depends on certain health beliefs, such as health risk, prognosis, and stigma (Tu and Hargraves, 2003). At the same time, it is also not unaffected by socio-contextual factors and psychosocial causes. Hence, better understanding of individuals' social conditions must be promoted.

\section{Contextual Determinants of HISB}

\section{Community characteristics}

Community characteristics such as community size, population density, average monthly income, financial independence, length of residence, community-based organizations, poverty, crime, and migration may influence the capacity of local residents and health communication behaviors (Jung and Choi, 2013). In a small community with high population density, community participation is low and communication between the residents is decreased (Rothenbuler et al., 1996). This is because the population density of a community is associated with attachment and social cohesion in a reverse U-shape. Moderate population density is thus an ideal condition for communal communication. Furthermore, in the case of communities of comparable size, more associational ties result in better health communication (Viswanath et al., 2006). Meanwhile, it has been reported that in conditions of high population density, television is the main source of information on the pending issues in the community, whereas in conditions of low population density the newspaper is the main information source (Rothenbuler et al., 1996). One possible explanation is that local residents in larger communities rely on mass media more than community networks, while those in smaller communities reinforce attachment through community ties (Olien et al., 1985). Lastly, stronger community attachment and community identity promote more grassroots organizations and local media, facilitating local residents' health communication behaviors (Rothenbuler et al., 1996). Community attachment reflects local residents' sense of belonging and social support, which revitalize cognitive interaction and communication among residents.

\section{Neighborhood social capital}

Neighborhood social capital that serves as the social network among the local residents and organizations in the community contributes to enhancing the overall communication and social cohesion of a community (McLeod et al., 1999; Moy et al., 2004; Viswanath et al., 1990). Community networks can exert influences over media exposure through social priming (Demers, 1996). The interactions between community residents and community-based voluntary associations prime audiences for broader exchange and navigation of health information. Residents' newspaper subscription actually enhances their community participation and membership while increasing their interdependence (Viswanath et al., 1990; Rothenbuler et al., 1996). Therefore, overall community capacity stays high in areas with a high level of neighborhood social capital. Such areas also show robust health communication, because it takes active involvement to solve numerous health issues about which communities communicate (Viswanath et al., 1990; Kang and Kwak, 2003; Jung and Viswanath, 2013). Many studies have so far reported that the use of news media, such as TV or newspaper, has a positive correlation with social capital and trust, group membership, and civic participation (Beaudoin and Thorson, 2004; Shah et al., 2001; Besley, 2006; Shah, 2001). This is probably because news media create opportunities for discussion about current issues in the community and spearhead the troubleshooting process through the exchange of opinions (Beaudoin et al., 2006; Shah et al., 2001). Health communication among residents can be boosted by the interaction between the media and neighborhood social capital.

\section{Media advocacy}

Under certain circumstances, the media can contribute to amplifying the community agenda for social changes (Demers and Viswanath, 1999; Nessa et al., 2013; Saleh et al., 2012). Organized efforts for the promotion of public health, such as population-based health communication campaigns, often use the mass media as a powerful tool (Beaudoin et al., 2006). Collective action, commonly called "media advocacy," plays a vital role in community change by galvanizing attention and interest from community residents (Wallack and Dorfman, 1996; Radin, 2006). In practice, media advocacy is highly useful for resolving community issues and it fosters strong unity among residents while heightening community identity (Bracht and Tsouros, 1990; Kawachi and Berkman, 2000). When it comes to health issues, media advocacy is reported to encourage health communication and survivorship of patients, thereby resulting in overall improvements in health status (Bracht and Tsouros, 1990; Kawachi et al., 1999; Sampson et al., 1997; Jung, 2013).

\section{Outcomes of HISB}

So far, a large number of studies have reported that HISB improves individual healthcare management skills and medical compliance while being strongly associated with decreasing unhealthy behaviors and increasing medical service satisfaction and cooperative decision- 


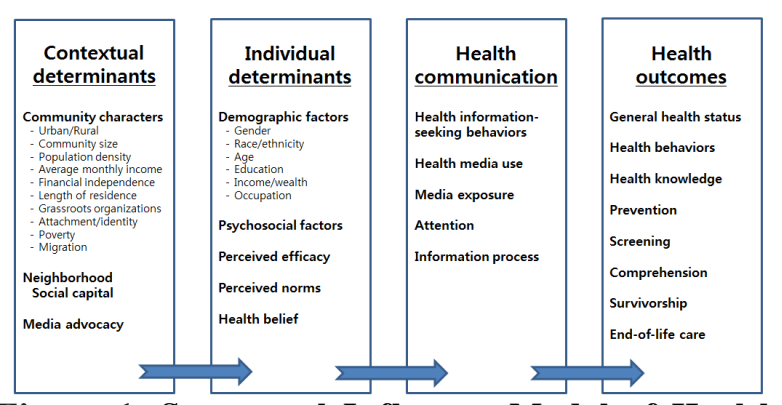

Figure 1. Structural Influence Model of Health Information-Seeking Behaviors

making (Briss et al., 2004; Gray et al., 2009; Hiatt and Rimer, 1999; Shi et al., 2004; Warner and Procaccino, 2004; Yu et al., 2008; Rutten et al., 2006; Jung, 2014). In practice, health information sourced from HISB is useful not only for handling health problems, but also for boosting self-efficacy, thereby fostering information-seeking behaviors and enhancing overall health communication capacity (Lee et al., 2008). Moreover, HISB helps to develop coping capacity, reduce unnecessary health concerns, and induce preventive behaviors through a variety of emotional supports (Johnson, 1997).

\section{Discussion}

As shown in Figure 1, this study examined individual and socio-contextual determinants of HISB. Based on the Structural Influence Model (SIM; Viswanath et al., 2007), Figure 1 shows multifaceted factors associated with HISB, thereby clarifying their impact on health outcomes. Individual determinants herein encompass not only education, income, and job, but also psychosocial elements, efficacy, and health belief (Ramanadhan and Viswanath, 2006; Viswanath, 2006). Such mediating factors affect health outcomes through cognitive factors (e.g., health knowledge and health belief), behavioral factors (e.g., behavioral capacity and preventive behavior), and medical treatment, while at the same time influencing population health through contextual factors, such as neighborhood social capital, and media advocacy, within the community. Therefore, we need to understand a population's health status as both the cumulative impact and output of socio-contextual determinants.

HISB, which makes structural differences depending on socio-contextual factors, may be affected by communication inequalities. Communication inequalities can be defined as gaps in the generation, manipulation, and distribution of information at the group level, and gaps in access to information and its benefits at the individual level (Viswanath, 2006; Jung, 2013). One of the potential causes of communication inequalities may be the nature of a social network and the degree of participation in the social network. It is highly probable that those who participate in voluntary associations may rank higher in socioeconomic status than those who do not. Such social networks can bring opportunities for learning more about health, and may consequently cause communication inequalities (Viswanath et al., 2006). For example, disparate social networks promote distribution and dissemination of new information through social capital or community mobilization (i.e., bridging the social network) as compared with other close network relations such as family or friends (i.e., bonding the social network). Consequently, it is necessary to give deep insight into health inequalities caused by structural differences in HISBs.

Under the current circumstances of the healthcare environment, it is essential to build patients' selfempowerment to seek out health information and induce patients to make informed decisions. Beyond simply increasing our knowledge on health information channels from now on, it is also necessary to look into what kinds of health information patients and their families search for and how this varies depending on SES and race. Additionally, it is also essential to look closely into the channels that are used by people of different SES to obtain health information, how people understand and make use of the health information, and finally, what health information is not acquired. In this respect, studies on HISB can bring us more effective health promotion and community-based interventions.

In conclusion, we took a brief look at social and individual determinants and results of HISBs in this study. At a time when epidemiological studies shift their focus to chronic diseases and active medical consumers come to the forefront, HISB is now gathering more momentum than ever before. Post-treatment cancer patients anticipate making more informed decisions about their medical treatment, and this trend is expected intensify as various types of treatment options become available through developments in biomedical science. Such medical developments occur concurrently with communication innovations that provide voluminous information through diverse information delivery platforms. Of the numerous types of healthcare needs, health information is the most basic (Duggan and Bates, 2008; Mayer et al., 2007). Therefore, it is very crucial to have an in-depth understanding of factors behind HISBs by post-treatment cancer patients, thereby enabling both patients and their families to gain a better capacity for health communication.

\section{References}

Ajzen I (1991). The theory of planned behavior. Organ Behav Human Decision Proc, 50, 179-211.

Arora NK, Hesse BW, Rimer BK, et al (2008). Frustrated and confused: The American public rates its cancer-related information-seeking experiences. J Gen Int Med, 23, 223-8.

Bandura A, Cervone D (1983). Self-evaluative and self-efficacy mechanisms governing the motivational effects of goal systems. J Personal Soc Psychol, 45, 1017-28.

Bass S, Ruzek S, Gordon T, et al (2006). Relationship of internet health information use with patient behavior and selfefficacy: Experiences of newly diagnosed cancer patients who contact the national cancer institute's cancer information service. J Health Comm, 11, 219-36.

Beaudoin CE, Thorson E, Hong T (2006). Promoting youth health by social empowerment: A media campaign targeting social capital. Health Comm, 19, 175-82.

Beaudoin CE, Thorson E (2004). Social capital in rural and urban communities: Testing differences in media effects 
and models. Journalism Mass Communication Quarterly, 81, 378-399.

Besley JC (2006). The role of entertainment television and its interactions with individual values in explaining political participation. Harvard Int J Press-Politic, 11, 41-63.

Borgers R, Mullen PD, Meertens R, et al (1993). The informationseeking behavior of cancer outpatients: A description of the situation. Patient Educ Counsel, 22, 35-46.

Bracht N, Tsouros A(1990). Principles and strategies of effective community participation. Health Promot Int, 5, 199-208.

Brashers DE, Goldsmith DJ, Hsieh EI (2002). Information seeking and avoiding in health contexts. Human Comm Res, 28, 258-71.

Briss P, Rimer B, Reilley B, et al (2004). Promoting informed decisions about cancer screening in communities and healthcare systems. Am J Prevent Med, 26, 67-80.

Butow PN, Maclean M, Dunn SM, Tattersall MHN, Boyer MJ (1997). The dynamics of change: Cancer patients' preferences for information, involvement and support. Ann Oncol, 8, 857-63.

Case DO, Andrews JE, Johnson JD, Allard SL (2005). Avoiding versus seeking: The relationship of information seeking to avoidance, blunting, coping, dissonance, and related concepts. J Med Lib Assoc, 93, 353-62.

Czaja R, Manfredi C, Price J (2003). The determinants and consequences of information seeking among cancer patients. $J$ Health Comm, 8, 529-62.

Demers DP (1996). Dose personal experience in a community increase or decrease newspaper reading? J Mass Comm Quart, 73, 304-18.

Demers D, Viswanath K (1999). What promotes or hinders the role of mass media as an agent of social control or social change: A macrosocial perspective. Ames, IA: Iowa State University Press.

Duggan D, Bates I (2008). Medicine information needs of patients: The relationships between information needs, diagnosis and disease. Qua Saf Health Care, 17, 85-89.

Eakin EG, Strycker LA (2001). Awareness and barriers to use of cancer support and information resources by HMO patients with breast, prostate, or colon cancer: Patient and provider perspectives. Psycho-Oncol, 10, 103-13.

Echlin KN, Rees CE (2002). Information needs and informationseeking behaviors of men with prostate cancer and their partners: A review of the literature. Cancer Nurs, 25, 35-41.

Eng TC, Yaakup H, Shah SA, Jaffar A, Omar K (2012). Preferences of Malaysian cancer patients in communication of bad news. Asian Pac J Cancer Prev, 13, 2749-52.

Fallowfield L, Ford S, Lewis S (1995). No news is not good news: Information preferences of patients with cancer. Psycho-Oncol, 4, 197-202.

Feltwell AK, Rees CE (2004). The information-seeking behaviours of partners of men with prostate cancer: A qualitative pilot study. Patient Educ Counsel, 54, 179-85.

Fishbein M, Cappella J, Hornick R, Yzer M, Ahern RK (2002). The role of theory in developing effective anti-drug public service announcements. In: Crano WD, Burgoon M (eds) Mass media and drug prevention: Classic and contemporary theories and research (pp. 89-118). Mahwah, NJ: Erlbaum.

Fox S, Jones S (2009). The social life of health information. Washington, DC: Pew Internet \& American Life Project.

Galarce EM, Ramanadhan S, Crisostomo J, et al (2010). Barriers to accessing internet health information among cancer patients and survivors. Paper presented at the Society of Behavioral Medicine, Seattle, USA.

Gray SW, O'Grady C, Karp L, et al (2009). Risk information exposure and direct-to-consumer genetic testing for BRCA mutations among women with a personal or family history of breast or ovarian cancer. Cancer Epi Biomarker Prev,
18, 1303-11.

Hesse BW, Nelson DE, Kreps GL, et al (2005). Trust and sources of health information: The impact of the internet and its implications for health care providers: Findings from the first Health Information National Trends Survey. Arch Int Med, 165, 2618-24.

Hiatt RA, Rimer BK (1999). A new strategy for cancer control research. Cancer Epi Biomarker Prev, 8, 957-64.

Institute of Medicine (2004). Health literacy: A prescription to end confusion. Washington, DC: National Academy Press.

Irving G, Lloyd-Williams M (2010). Depression in advanced cancer. Euro J Oncol Nurs, 14, 395-99.

Johnson JD (1997). Cancer-related information seeking. Cresskill, NJ: Hampton Press.

Johnson JD, Meischke H (1991). Women's preferences for cancer information from specific communication channels. Am Behav Sci, 34, 742-55.

Jung M, Ramanadhan S, Viswanath K (2013). Effect of information seeking and avoidance behavior on self-rated health status among cancer survivors. Patient Educ Counsel, 92, 100-6.

Jung M, Viswanath K (2013). Does community capacity influence self-rated health? Multilevel contextual effects in Seoul, Korea. Soc Sci Med, 77, 60-9.

Jung M, Choi M (2013). Impact of community capacity on the health status of residents: understanding with the contextual multilevel model. Health Care Manag, 32, 77-86.

Jung M (2013). Cancer control and the communication innovation in South Korea: implications for cancer disparities. Asian Pac J Cancer Prev, 14, 3411-7.

Jung M (2014). Associations of self-rated health and socioeconomic status with information seeking and avoiding behavior among post- treatment cancer patients. Asian Pac J Cancer Prev, 15, 2231-8.

Kahlor L (2010). PRISM: A planned risk information seeking model. Health Comm, 25, 197-211.

Kawachi I, Berkman L (2000). Social cohesion, social capital and health. In: Berkman L, Kawachi I (eds) Social Epidemiology (pp. 174-190). New York: Oxford University Press.

Kawachi I, Kennedy BP, Glass R (1999). Social capital and self-rated health: A contextual analysis. Am J Public Health, 89, 1187-93.

Kang N, Kwak N (2003). A multilevel approach to civic participation - Individual length of residence, neighborhood residential stability, and their interactive effects with media use. Comm Res, 30, 80-106.

Kelly KM, Sturm AC, Kemp K, Holland J, Ferketich AK (2009). How can we reach them? Information seeking and preferences for a cancer family history campaign in underserved communities. J Health Comm, 14, 573-89.

Lambert SD, Loiselle CG (2007). Health information seeking behavior. Qual Health Res, 17, 1006-19.

Lee SY, Hwang H, Hawkins R, Pingree S (2008). Interplay of negative emotion and health self-efficacy on the use of health information and its outcomes. Comm Res, 35, 358-81.

Lenz E (1984). Information seeking: A component of client decisions and health behavior. Advan Nurs Sci, 6, 59-71.

Levinson W, Kao A, Kuby A, Thisted RA (2005). Not all patients want to participate in decision making. J Gen Int Med, 20, 531-5.

Lewis N, Gray SW, Freres DR, Hornik RC (2009). Examining cross-source engagement with cancer-related information and its impact on doctor-patient relations. Health Comm, 24, 723-34.

Loiselle CG, Lambert SD, Cooke A (2006). The searching, processing, and sharing of breast cancer information by women diagnosed with the illness. Canadian J Nursing Res, 38, 82-104. 
Maguire P, Faulkner A, Booth K, Elliott C, Hillier V (1996). Helping cancer patients disclose their concerns. Euro $J$ Cancer Care, 32, 78-81.

Maliski SL, Connor S, Fink A, Litwin MS (2006). Information desired and acquired by men with prostate cancer: Data from ethnic focus groups. Health Educ Behav, 33, 393-409.

Mayer DK, Terrin NC, Kreps GL, et al (2007). Cancer survivors' information seeking behaviors: A comparison of survivors who do and do not seek information about cancer. Patient Educ Counsel, 65, 342-50.

McCloud RF, Jung M, Gray SW, Viswanath K (2013). Class, race and ethnicity and information avoidance among cancer survivors. Br J Cancer, 108, 1949-56.

McLeod JM, Scheufele DA, Moy P (1999). Community, communication, and participation: The role of mass media in interpersonal discussion in local political participation. Polit Comm, 16, 315-36.

Miller SM (1987). Monitoring and blunting: Validation of a questionnaire to assess styles of information seeking under threat. J Personal Soc Psychol, 52, 345-53.

Moy P, McCluskey MR, McCoy K, Spratt MA (2004). Political correlates of local news media use. J Comm, 54, 532-46.

Muha C (1998). The use and selection of sources in information seeking: The cancer information service experience. J Health Comm, 3, 109-20.

Nessa A, Hussain MA, Rashid MH, et al (2013) Role of print and audiovisual media in cervical cancer prevention in Bangladesh. Asian Pac J Cancer Prev, 14, 3131-7.

Nguyen GT, Bellamy SL (2006). Cancer information seeking preferences and experiences: Disparities between Asian Americans and whites in the Health Information National Trends Survey (HINTS). J Health Comm, 11, 173-80.

Olien CN, Donohue GA, Tichenor PJ (1985). Community structure, newspaper use and community attachment. Paper presented at the annual conference of the American Association for Public Opinion Research, McAfee, NJ: USA.

Pinquart M, Duberstein PR (2004). Information needs and decision-making processes in older cancer patients. Crit Rev Oncol/Hematol, 51, 69-80.

Radecki CM, Jaccard J (1995). Perceptions of knowledge, actual knowledge, and information search behavior. J Experiment Soc Psychol, 31, 107-38.

Radin P (2006). To me, it's my life: Medical communication, trust, and activism in cyberspace. Soc Sci Med, 62, 591-601.

Ramanadhan S, Viswanath K (2006). Health and the information nonseeker: A profile. Health Comm, 20, 131-9.

Rothenbuler EW, Mullen LJ, DeLaurell R, Ryu CR (1996). Communication, community attachment, and involvement. Journalism Mass Comm Quart, 73, 445-66.

Rutten LJF, Squiers L, Hesse B (2006). Cancer-related information seeking: Hints from the 2003 Health Information National Trends Survey (HINTS). J Health Comm, 11, 147-56.

Saleh A, Yang YH, Wan Abd Ghani WM, et al (2012) Promoting oral cancer awareness and early detection using a mass media approach. Asian Pac J Cancer Prev, 13, 1217-24.

Sampson RJ, Raudenbush SW, Earls F (1997). Neighborhoods and violent crime: A multilevel study of collective efficacy. Science, 277, 918-924.

Serin D, Dilhuydy JM, Romestaing P, et al (2004). Parcours de femme 2001: A French opinion survey on overall disease and everyday life management in 1870 women presenting with gynecological or breast cancer and their caregivers. Annal Oncol, 15, 1056-64.

Shah DV, Kwak N, Holbert RL (2001). Connecting and disconnecting with civic life: Patterns of Internet use and the production of social capital. Polit Comm, 18, 141-62.

Shah DV, McLeod JM, Yoon SH (2001). Communication, context, and community -An exploration of print, broadcast, and Internet influences. Comm Res, 28, 464-506.

Shi H-J, Nakamura K, Takano T (2004). Health values and health-information-seeking in relation to positive change of health practice among middle-aged urban men. Prev Med, 39, 1164-71.

Shieh C, Mays R, McDaniel A, Yu J (2009). Health literacy and its association with the use of information sources and with barriers to information seeking in clinic-based pregnant women. Health Care Women Int, 30, 971-88.

Shim M, Kelly B, Hornik R (2006). Cancer information scanning and seeking behavior is associated with knowledge, lifestyle choices, and screening. J Health Comm, 11, 157-72.

Sullivan HW, Finney Rutten LJ (2009). Cancer prevention information seeking: A signal detection analysis of data from the cancer information service. J Health Comm, 14, 785-96.

Tu HT, Hargraves JL (2003). Seeking health care information: Most consumers still on the sidelines. Issue BriefCent Stud Health Syst Change, 61, 1-4.

Vanderpool RC, Kornfeld J, Finney Rutten L, Squiers L (2009). Cancer information-seeking experiences: The implications of Hispanic ethnicity and Spanish language.J Cancer Educ, 24, 141-7.

Van der Molem B (1999). Relating information needs to the cancer experience: 1 . Information as a key coping strategy. Euro J Cancer Care, 8, 238-44.

Viswanth K, Finnegan JR, Rooney B, Potter J (1990). Community ties and the use of newspapers and cable TV in a rural Midwestern community. Journalism Quart, 67, 899-911.

Viswanath K (2005). The communications revolution and cancer control. Nature Rev Cancer, 5, 828-35.

Viswanath K (2006). Public communications and its role in reducing and eliminating health disparities. In: Thomson GE, Mitchell F, Williams MB (eds) Examining the health disparities research plan of the national institutes of health: Unfinished business (pp. 215-253). Washington, DC: Institute of Medicine.

Viswanth K, Randolph W, Finnegan JR (2006). Social capital and health: civic engagement, community size, and recall of health messages. Am J Public Health, 96, 1456-61.

Viswanath K, Breen N, Meissner H, et al (2006). Cancer knowledge and disparities in the information age. J Health Comm, 11, 1-17.

Viswanath K, Kreuter MW (2007). Health disparities, communication inequalities, and e-health. Am J Prev Med, 32, 131-3.

Viswanath K, Ramanadhan S, Kontos EZ (2007). Mass media and population health: A macrosocial view. In: Galea S (ed) Macrosocial Determinants of Population Health (pp. 275294). New York: Springer.

Viswanath K, Nagler RH, Bigman-Galimore CA, et al (2012). The communications revolution and health inequalities in the 21st century: Implications for cancer control. Cancer Epi, Biomarker Prev, 21, 1701-8.

Wallack L, Dorfman L (1996). Media advocacy: A strategy for advancing policy and promoting health. Health Educ Quart, 23, 293-317.

Warner D, Procaccino JD (2004). Toward wellness: Women seeking health information. J Am Soc Info Sci Tech, 55, 709-30.

Whetten K, Reif S, Whetten R, Murphy-McMillan LK (2008). Trauma, mental health, distrust, and stigma among HIV-positive persons: Implications for effective care. Psychosomatic Med, 70, 531-8.

Yu MY, Wu TY (2005). Factors influencing mammography screening of Chinese American women. J Obstet Gynecol Neonatal Nurs, 34, 386-94. 